\title{
Arterial tortuosity syndrome
}

INSERM

\section{Source}

INSERM. (1999). Orphanet: an online rare disease and orphan drug data base. Arterial tortuosity syndrome. ORPHA:3342

Arterial tortuosity syndrome (ATS) is a rare connective tissue disorder characterized by tortuosity and elong ation of the large and medium-sized arteries and a propensity towards aneurysm formation, vascular dissection, and stenosis of the pulmonary arteries. 